\title{
Ten years (2004-20I4) of Chagas disease surveillance and vector control in Ecuador: successes and challenges
}

\author{
Leonardo Quinde-Calderón', Paulina Rios-Quituizaca ${ }^{2}$, Luis Solorzano ${ }^{3}$ and Eric Dumonteil ${ }^{3,4}$ \\ 1 Programa Nacional de Chagas, Leishmaniasis y Oncocercosis, Ministerio de Salud Pública, Guayaquil, Ecuador \\ 2 Facultad de Ciencias Médicas, Universidad Central del Ecuador, Quito, Ecuador \\ 3 Subproceso de Parasitologia, Instituto Nacional de Investigación en Salud Pública, Guayaquil, Ecuador \\ 4 Laboratorio de Parasitología, Centro de Investigaciones Regionales "Hideyo Noguchi”, Universidad Autónoma de Yucatán, Mérida, \\ Yucatán, México
}

\begin{abstract}
овjective To describe the current situation of Chagas disease in Ecuador and to evaluate the impact of vector control for the period 2004-2014.

METHODS Since 2004, the Ministry of Public Health has formalized activities for the surveillance and control of Chagas disease and we analyzed here available records.

RESULTS More than 200000 houses were surveyed, and $2.6 \%$ were found to be infested $195 \% \mathrm{CI}$ :

2.6-2.7), and more than 51000 houses were sprayed with residual insecticide, with important yearly variations. A total of 915 cases of T. cruzi infection were registered. The Amazon region is emerging as a high priority area, where nearly half of $T$. cruzi infection cases originate. The costal region and the southern highland valleys remain important high-risk area. Vector control efforts over the past 10 years have been effective in the coastal region, where $T$. dimidiata predominates, and resulted in important reductions in house infestation indices in many areas, even reaching negligible levels in some parishes.

CONCLUSion Vector efforts need to be sustained and expanded for the elimination of $T$. dimidiata to be feasible. Novel vector control interventions need to be designed to reduce intrusion by several triatomine species present in the Amazon region and southern Ecuador. Strong political commitment is needed to sustain current achievements and improve the national coverage of these programmes.
\end{abstract}

keywords Trypanosoma cruzi, American Trypanosomiasis, insecticide

\section{Introduction}

Chagas disease, or American tripanosomiasis, is caused by the protozoan parasite Trypanosoma cruzi, which is transmitted through the faeces of hematophagous insects of the triatomine family. Following a short acute phase, infected patients enter an initially asymptomatic chronic phase. $30-40 \%$ then evolve into a symptomatic chronic phase, characterised by a Chagasic cardiomyopathy and/ or digestive megasyndromes [1].

Chagas disease in a major public health in Latin America, where current estimates suggest a total of nearly 6 million cases [2]. It causes healthcare costs of $\$ 24$ billion and a burden of 29385250 Disease Adjusted Life Years (DALYs) [3]. Despite this, it is a neglected disease, disproportionately affecting poor populations [4, 5]. In Ecuador, there are an estimated 100-200 000 cases and both the cardiac and the digestive forms of the chronic phase have been observed [6]. The seroprevalence of T. cruzi infection is highly variable among the provinces, ranging from $<1$ to $5-6 \%$, with a national average of $0.7 \%$ [6-8]. In 1978, Chagas disease notification became mandatory in Ecuador, which also joined the intergovernmental Initiative of Andean Countries for Chagas Disease Control in 1997.

The main vector species in Ecuador are Triatoma dimidiata and Rhodnius ecuadoriensis, and several additional species are considered secondary vectors, particulary in the Amazon region [9, 10]. T. dimidiata is present in most of the coastal region, but unconnected to populations from Colombia and hence considered an introduced species [9, 10]. Preliminary molecular analysis supports the possible introduction of $T$. dimidiata from Central America (Nicaragua, Honduras) in colonial times [1113]. The elimination of $T$. dimidiata from Ecuador by residual insecticide spraying is thus an important goal of 
vector control activities [10]. R. ecuadoriensis has been found in diverse habitats, with different levels of domiciliation according to the region [14-18]. It is believed to be controllable by insecticide spraying as well.

Since 2004, the Ministry of Public Health of Ecuador has formalised activities for the epidemiologic and entomologic surveillance of Chagas disease, as well as vector control activities, through the Instituto Nacional de Investigación en Salud Pública (INSPI, National Institute for Research in Public Health) and the Servicio Nacional de Control y Vigilancia de enfermedades transmitidas por vectores artrópodos (SNEM, National Service for the Control and Surveillance of Diseases Transmitted by Arthropods) [19]. These programmes are intended to follow recommendations from a technical consultation through PAHO/WHO [20]. The objective of this work was to analyse the records of Chagas disease entomological and epidemiological surveillance activities from the Ministry of Public Health, to obtain a description of the current situation in Ecuador and to evaluate the impact of vector control activities over the past 10 years (20042014). Such analyses of national programmes are valuable in assessing the efficacy of established policies and programmes and making adjustments when needed [21-27].

\section{Materials and methods}

\section{Ethical considerations}

All data were anonymous and used with the permission of the Ministry of Public Health of Ecuador.

\section{Entomological data}

Entomological records span the years 2004-2014 and are based on entomological collections by timed manual searches of domiciles and peridomiciles by trained vector control teams from the Ministry of Health, according to standard procedures [28]. Entomological surveillance started in 2004, and insecticide spraying was initiated in 2006. Both surveillance and insecticide spraying were conducted concurrently, although a response time of 1 12 months occured, due to logistical and financial constraints of the programme. Intradomiciliary insecticide spraying was performed with $5 \%$ deltamethrin wp, as well as in selected peridomestic sites, according to established guidelines [28]. All data were available at the province level for 2004-2006 and at the parish level since 2007. However, both surveillance and vector control activities were restricted to selected parishes within selected provinces that varied from year to year, based on the resources available to the surveillance and control programme (Table 1).

\section{Data from human cases}

Human case records span the years 1990-2014 and are based on both passive and active surveillance of cases. Only confirmed cases were included, based on the definitions of the Ministry of Public Health [28], that is cases with a positive direct parasitological test or at least two positive serological tests of different principles (ELISA, indirect hemagglutination assay and/or indirect immunofluorescence) [8]. Data were available at the parish level for all years.

\section{Statistical analysis}

Data were summarised by year, at the parish or province level, depending on data availability, and for the entire study period. We focused on the infestation index (proportion of houses infested by triatomines), and on the intensity of vector control interventions, which was considered as the number of houses sprayed each year. Maps of triatomine infestation and human cases distribution were elaborated in QGIS 1.7 [29]. Geographic and environmental data were obtained from the Instituto Nacional de Estadisticas y Censos (INEC, National Institute of Statistics and Census, http://www.ecuadorencifras.gob.ec/).

Linear mixed models were used to evaluate the associations between vector control activities and changes in triatomine infestation levels. Only parishes and provinces for which data were available for at least 3 years were included in the analysis. Because data were grouped by year, a lag time of 1-12 months between spraying and follow-up surveillance was included into our analysis. A lag time of 13-24 months was also tested by shifting infestation data accordingly, in comparison with insecticide spraying data. The models were adjusted using restricted maximum likelihood (REML). The infestation index was log-transformed, to better satisfy a normal distribution and other model assumptions [23]. As in previous studies, we accounted in some models for the potential non-independence of repeated surveys in the same parishes and provinces by considering them as a random factor, and temporal autocorrelation (year) was specified as a fixed effect [23]. The fit of the models was assessed by comparing predicted and observed house infestation, and model comparisons were based on Akaike information criteria (AIC) and Bayesian information criteria (BIC). All analyses were performed in JMP 9.0 (SAS Institute Inc., Carry, NC, USA). 


\section{Results}

Entomological surveillance and vector control efforts

Active entomological surveillance for triatomine infestation partially covered 11 provinces; 12 have never been investigated. However, not all 11 provinces were surveyed every year, nor were all parishes of these provinces covered. Some parishes were studied repeatedly, others less frequently (Table 1). Overall, more than 200000 houses were surveyed between 2004 and 2014, and more than 5000 were found to be infested, giving an overall infestation index of $2.6 \%$ (95\% CI: 2.6-2.7) (Table 1). In response to this infestation, more than 51000 houses were sprayed with residual insecticide, with large variations from year to year depending on the resources available for the vector control programme (Table 1).

House infestation was reported in 8 of 11 provinces: El Oro, Guayas, Loja, Manabí, Orellana, Pichincha, Santo Domingo de los Tsáchilas and Sucumbios, with infestation levels ranging from $0.2 \%$ up to $29 \%$, and no infestation was found in the provinces of Los Ríos, Santa Elena, and Zamora Chinchipe (Figure 1). A total of nearly 60000 triatomines were collected, of which 36035 had taxonomic information. The most frequently reported species was $T$. dimidiata $(86 \%)$ followed by R. ecuadoriensis (12\%), which were observed in the western and southern provinces, and they represent the main vector species. Secondary species detected included Panstrongylus rufotuberculatus (1\%), Triatoma carrioni $(0.3 \%)$, P. howardi $(0.1 \%)$, P. geniculatus $(<0.1 \%)$, $P$. chinai $(<0.1 \%)$, R. pictipes $(<0.1 \%)$ and $R$. robustus $(<0.1 \%)$, mostly in the Amazon and southern region of the country.

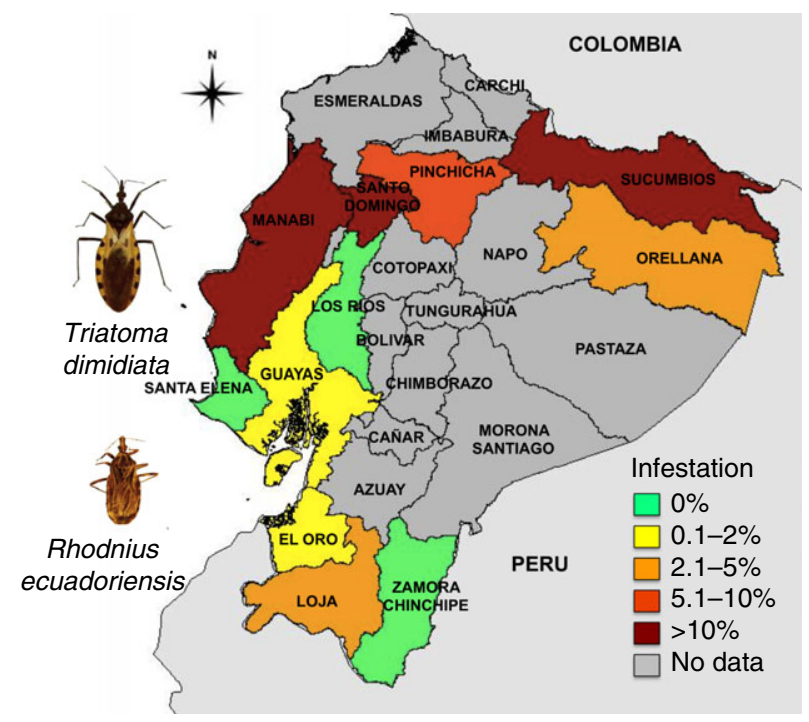

Figure I Map of house infestation for years 2004-2014. House infestation was calculated at the province level over the years 2004-2014, based on active entomological surveillance as explained in the Materials and Methods section. The colour codes represent the indicated infestation levels. There is no data reported for 12 provinces. The main vectors species in the western and southern regions are $T$. dimidiata $(86 \%$ of collected bugs) and $R$. ecuadoriensis (12\%).

\section{Epidemiologic surveillance}

A total of 915 cases of T. cruzi infection have been registered by the Ministry of Public Health over the years 1990-2014, with a gradual increase over the years, which likely represented improvements in case

Table I Infestation by triatomines and vector control efforts in Ecuador

\begin{tabular}{|c|c|c|c|c|c|c|}
\hline Year & $\begin{array}{l}\text { Number of } \\
\text { provinces studied }\end{array}$ & $\begin{array}{l}\text { Number of } \\
\text { parishes studied }\end{array}$ & $\begin{array}{l}\text { Number of } \\
\text { houses studied }\end{array}$ & $\begin{array}{l}\text { Number of } \\
\text { infested houses }\end{array}$ & $\begin{array}{l}\text { Infestation } \\
\text { index }[95 \% \mathrm{CI}]\end{array}$ & $\begin{array}{l}\text { Number of } \\
\text { houses sprayed }\end{array}$ \\
\hline 2004 & 6 & NR & 7639 & 205 & $2.7[2.3-3.1]$ & 0 \\
\hline 2005 & 8 & NR & 22511 & 746 & $3.3[3.1-3.6]$ & 0 \\
\hline 2006 & 8 & NR & 30994 & 1700 & $5.5[5.2-5.7]$ & 7320 \\
\hline 2007 & 1 & 12 & 10567 & 156 & $1.5[1.3-1.7]$ & 326 \\
\hline 2008 & 2 & 8 & 11831 & 162 & $1.4[1.2-1.6]$ & 917 \\
\hline 2009 & 6 & 57 & 45240 & 714 & $1.6[1.5-1.7]$ & 3605 \\
\hline 2010 & 4 & 23 & 15539 & 445 & $2.9[2.6-3.1]$ & 2641 \\
\hline 2011 & 3 & 26 & 19117 & 421 & $2.2[2.0-2.4]$ & 1982 \\
\hline 2012 & 4 & 22 & 23366 & 571 & $2.4[2.2-2.6]$ & 22630 \\
\hline 2013 & 3 & 13 & 10677 & 152 & $1.4[1.2-1.7]$ & 9577 \\
\hline 2014 & 1 & 7 & 3499 & 20 & $0.6[0.4-0.9]$ & 2367 \\
\hline Total & - & - & 200980 & 5292 & $2.6[2.6-2.7]$ & 51365 \\
\hline
\end{tabular}

NR, data not reported at the parish level but only at the province level. 

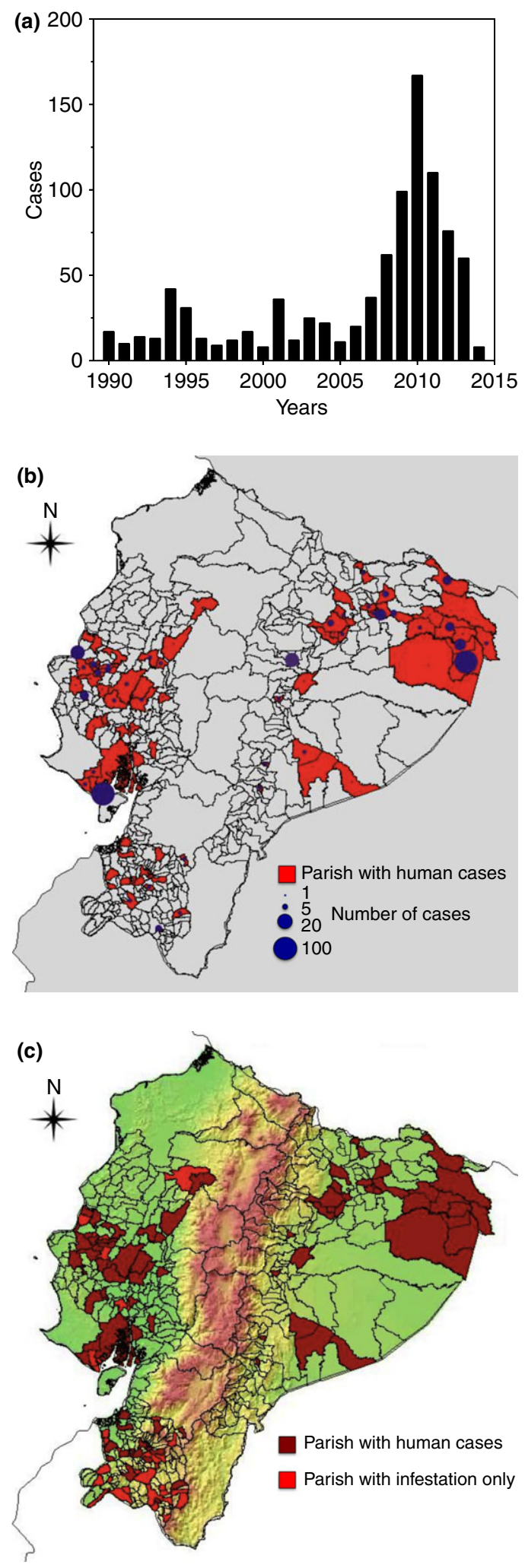

Figure 2 Human cases distribution and cumulative risk areas. (a) Number of human cases in Ecuador from 1990 to 2014. (b) Geographic distribution of cases at the parish level. Parishes with human cases are indicated in red. The size of the blue circles is proportional to the number of cases as indicated. (c) Combined distribution of human cases and house infestation by triatomines at the parish level.

reporting (Figure 2a). Cases originated from 11 provinces (El Oro, Guayas, Loja, Los Ríos, Manabí, Morona Santiago, Napo, Orellana, Pastaza, Santo Domingo de los Tsáchilas and Sucumbios). About half of the cases (415 cases, $45 \%$ ) were from the Ecuadorian Amazon region; the other half were distributed in the western coastal area (334 cases, 36\%) and the southern highland valleys of the western Andes (166 cases, $18 \%$ ) (Figure $2 \mathrm{~b}$ ). Importantly, in several instances, human cases were registered from parishes where no house infestation had been detected/reported through the vector surveillance programme. Conversely, in a few instances, particularly in the southern region, house infestation had been detected in many parishes but few human cases were recorded. Thus, combining human cases distribution with house infestation distribution allowed to identify a greater area in which T. cruzi transmission to humans may be occurring (Figure 2c). This map indicated three ecological regions with potential/demonstrated T. cruzi transmission to humans: (i) the western coastal region, where $T$. dimidiata predominates followed by $R$. ecuadoriensis; (ii) the southern highland valleys of the western Andes, where $R$. ecuadoriensis is the principal vector; and (iii) the Ecuadorian Amazon, where several vector species can invade houses. Importantly, neither human cases nor house infestation were recorded for most of the higher elevation Andean region.

\section{Impact of the vector control programme}

Vector control activities were initiated in 2006, covering over 51000 houses with indoor residual deltamethrin spraying during the period 2006-2014 (Table 1). Nonetheless, as with entomological surveillance, the coverage of vector control was irregular and varied from year to year based on available resources, although the number of houses sprayed tended to rise over time in most regions (Figure 3). The data suggest that the sporadic insecticide spraying in a small number of houses performed in the initial years had limited effect on house infestation, as seen in Manabí or Loja. However, more sustained spraying of a larger numbers of houses in later years did lead to significant reduc- 
L. Quinde-Calderón et al. Chagas disease in Ecuador
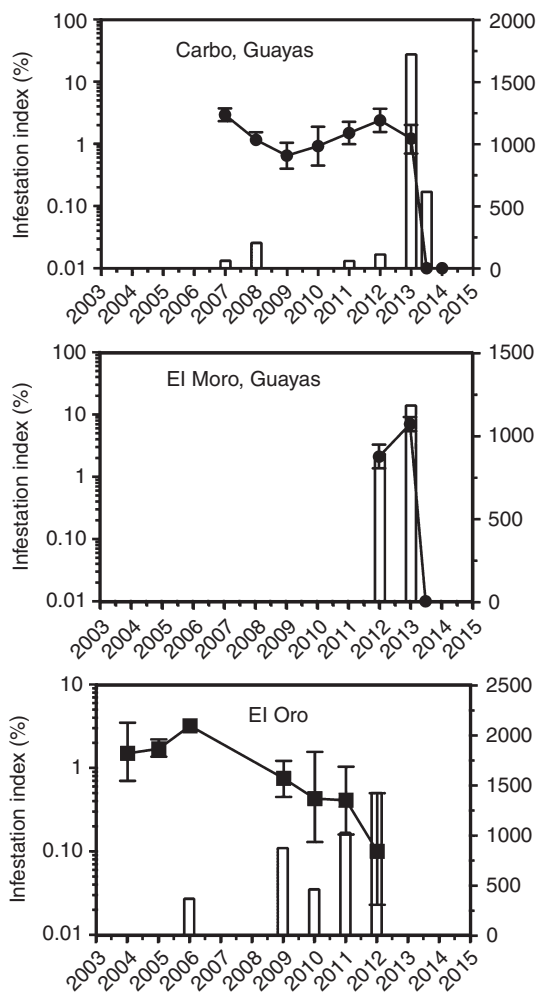
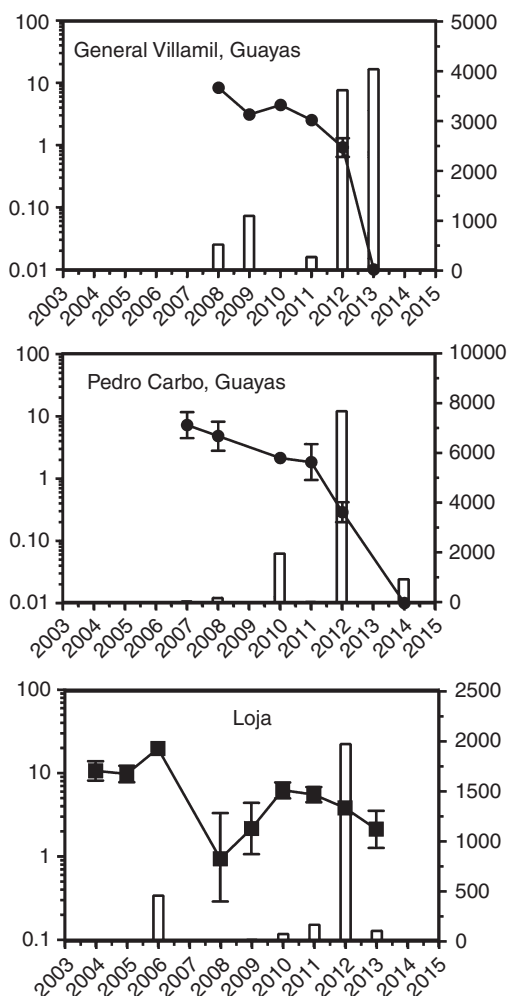
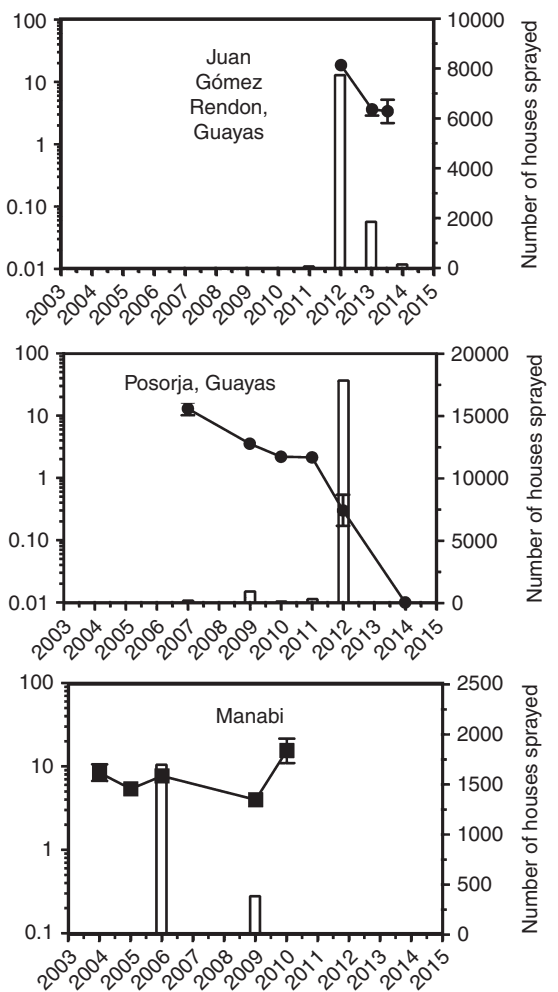

Figure 3 Impact of vector control efforts on house infestation. Changes in house infestation index (black circles, with $95 \%$ CI, left axis) over the years are shown, as well as the number of houses sprayed (white bars, right axis), for six parishes of the Guayas province (Carbo, General Villamil, Juan Gómez Rendon, El Moro, Pedro Carbo and Posorja) and for the provinces of El Oro, Loja and Manabí.

tions in house infestation in most parishes of the province of Guayas, in the provinces of El Oro and to a lesser extent in Loja (Figure 3). Modelling confirmed the strong association between the increased intensity of the vector control intervention, expressed as the number of houses sprayed each year, and a decrease in house infestation with an included lag time of up to 1 year (whole model: $P<0.001$, AIC $=133.3 ; \mathrm{BIC}=148.1$; Table 2). The model also included the years as a fixed effect covariate, as well as the parish/province as a random effect (Table 2). The fit of the model was very good, with a $R^{2}$ between observed and predicted infestation of 0.78 (Figure 4), and the decrease in house infestation was the strongest in recent years, when insecticide spraying intensified. No trends were observed in the residuals. Assuming a longer lag time of up to 2 years did not result in a better model (whole model: $P<0.001$, AIC $=132.0 ; \mathrm{BIC}=145.8)$, but the significant effect of insecticide spraying was lost $(P=0.82)$, suggesting that its effectiveness is not sustained beyond 1 year.

\section{Discussion}

We analysed the records of entomologic and epidemiologic surveillance of triatomines and Chagas disease cases from the Ministry of Public Health of Ecuador, to evaluate the current situation of Chagas disease in the country and the impact of vector control efforts over the past 10 years. (2004-2014). This type of analysis has been found to be highly valuable to assess programme effectiveness, as well as to provide cues to improvements in their implementation in several other countries [22]. For example, community participation proved very helpful in strengthening Chagas disease surveillance and control in Honduras [26]; while in Argentina [27]; in Guatemala [25] and in Cochabamba, Bolivia [23], among others, the efficacy of vector control activities has been confirmed.

Chagas disease surveillance and control programmes were implemented in Ecuador largely upon recommendation of an extensive consultation by $\mathrm{PAHO} / \mathrm{WHO}$, which summarised the situation in the early 2000, and made 
L. Quinde-Calderón et al. Chagas disease in Ecuador

Table 2 Modelling of the association between house infestation and insecticide spraying intensity

\begin{tabular}{|c|c|c|c|c|c|}
\hline & Coefficient estimate & & SE & {$[95 \% \mathrm{CI}]$} & $P$ value \\
\hline \multicolumn{6}{|l|}{ Fixed effects } \\
\hline Intercept & -1.155137 & & 0.3105 & {$[-1.7848 ;-0.5254]$} & $0.0007 *$ \\
\hline Year [2005-2004] & -0.0585 & & 0.3614 & {$[-0.7983 ; 0.6812]$} & 0.8724 \\
\hline Year [2006-2005] & 0.2987 & & 0.3622 & {$[-0.4428 ; 1.0402]$} & 0.4165 \\
\hline Year [2007-2006] & -0.1601 & & 0.4088 & {$[-0.9923 ; 0.6721]$} & 0.6979 \\
\hline Year [2008-2007] & -0.3941 & & 0.3532 & {$[-1.1156 ; 0.3273]$} & 0.2733 \\
\hline Year [2009-2008] & -0.0800 & & 0.2972 & {$[-0.6874 ; 0.5272]$} & 0.7895 \\
\hline Year [2010-2009] & 0.1169 & & 0.2483 & {$[-0.3911 ; 0.6251]$} & 0.6411 \\
\hline Year [2011-2010] & -0.1229 & & 0.2485 & {$[-0.6315 ; 0.3854]$} & 0.6244 \\
\hline Year [2012-2011] & -0.1029 & & 0.2762 & {$[-0.6657 ; 0.4598]$} & 0.7118 \\
\hline Year [2013-2012] & -0.2991 & & 0.2598 & {$[-0.8301 ; 0.2319]$} & 0.2589 \\
\hline Year [2014-2013] & -1.9932 & & 0.4426 & {$[-2.8923 ;-1.0941]$} & $<0.0001 *$ \\
\hline Spraying intensity & -0.000064 & & $2.912 \mathrm{e}-5$ & {$[-0.000123 ;-4.73 e-6]$} & $0.035^{*}$ \\
\hline \multicolumn{2}{|c|}{ Random effects: REML variance components } & Variance & SE & {$[95 \% \mathrm{CI}]$} & $\%$ of total variance \\
\hline \multicolumn{2}{|l|}{ Parish/province } & 0.1650 & 0.1209 & {$[-0.0719 ; 0.4020]$} & 45.7 \\
\hline \multicolumn{2}{|l|}{ Residual } & 0.1959 & 0.0519 & {$[0.1238 ; 0.3564]$} & 54.3 \\
\hline
\end{tabular}

The model takes into account a lag time of 1-12 months between insecticide spraying and house infestation. SE, standard error. *indicates significant $P$ values.

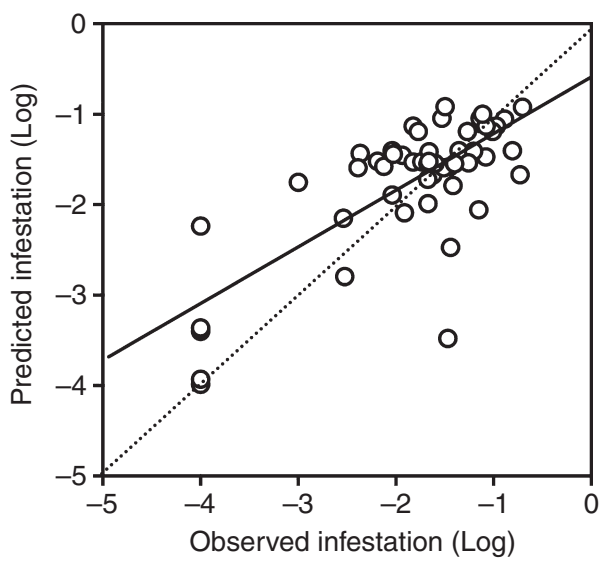

Figure 4 Comparison of observed and predicted infestation in response to vector control. The model provided a very good fit of observed and predicted infestation $\left(R^{2}=0.78\right)$, based on the intensity of insecticide spraying expressed as the number of houses sprayed each year, with the year as a fixed covariate and the geographic location (parish/province) as a random factor.

clear recommendations on the public health benefit of such programmes due to the high estimated burden of Chagas disease in the country [20]. This report identified the coastal region as well as the southern Andean valleys as high-risk regions that needed to be prioritised for Chagas disease surveillance and vector control, while the Amazon region was considered as intermediate risk and priority [20]. In response, the high-risk areas were the initial focus of surveillance activities, particularly for vector surveillance, although some limited work was done in provinces of the Amazon region. In fact, due to limited resources, both human and financial, there have been important variations in the geographic coverage of the surveillance activities, which focused on a variable number of provinces and parishes from year to year. Thus, a major limitation of the data analysed is that they do not correspond to a homogenous and systematic national coverage and may thus still present an incomplete picture of the distribution of Chagas disease in Ecuador. Also, because of limited follow-up after insecticide spraying (in most cases a single visit 1-12 months postintervention), so that vector surveillance and control could focus on new infested parishes, the data are somewhat biased towards a high infestation and tend to minimise the effect of insecticide spraying. Nonetheless, they provide highly valuable information on the current situation in at least parts of the country, some of which confirm previous estimates, while others are being challenged.

First, these data confirm the role of $T$. dimidiata and R. ecuadoriensis as primary vectors in the country, representing $98 \%$ of the vectors collected over the past 10 years. Infestation levels also remain significant in many parts of the country, strengthening the need for continued vector control activities. Second, there has been a marked increase in the number of registered cases, which likely reflect improvements in the epidemiologic 
surveillance system. However, the number of registered cases is still well below the estimated 100-200 000 cases $[6,20]$, and the difficulties in identifying more cases in recent years highlight the need for reinforced epidemiologic surveillance. In fact, previous studies have identified cases from almost all the provinces, with the notable exception of Chimborazo, Tungurahua, Cotopaxi and Carchi from the Andean region [20]. Thus, improvements in epidemiologic surveillance are still needed, and recent efforts at decentralising Chagas disease surveillance should help making diagnosis more readily available throughout the country.

Combining entomologic and epidemiologic data confirms the major Chagas disease risk areas, but still provides an incomplete picture of the distribution of the disease in Ecuador. Indeed, transmission is also very likely in most of parishes (and provinces) adjacent to those where it was reported, even though neither cases nor infestation have been reported to date. T. cruzi transmission was recently described in the province of Esmeralda in north-eastern Ecuador [30] and in Pastaza, in the Amazon region [31, 32]. Nonetheless, current data clearly indicate the existence of three major epidemiologic scenario for Chagas disease transmission in Ecuador $[6,20]$. The western coastal region is a confirmed highrisk region [33], where $T$. dimidiata predominates, although R. ecuadoriensis is also present. About $36 \%$ of all cases originate from this region. The Amazon region, which was initially classified as of medium risk [20], appears as the main source of cases in the country $(45 \%$ of cases) and should thus be considered a very high priority for surveillance and control [8]. Conversely, the southern highland valleys west of the Andes, previously classified as a high-risk area [20], only account for $18 \%$ of the cases, in spite of reports of frequent house infestation $[17,18]$ and a seroprevalence of $3.6 \%$ [7]. Further studies should confirm the possible epidemiological changes in the Amazon region, which may be associated with increasing deforestation [8].

Based on initial assessments [6, 20], vector control has been exclusively focused on the western coastal region and to a lesser extent, in the southern highland valleys. Importantly, to date, no vector control activities have taken place in the Amazon region, even though about half of the reported cases originate from this region. Our analysis confirms the significant efficacy of vector control activities over the past 10 years, in spite of their limitation and constraints, but highlights the need for sustained high coverage activities to ensure continued success. Indeed, the effect of insecticide spraying was significant only when infestation was monitored within a year postspraying, and it was lost when a longer time lag was considered. In fact, it seems clear that the proposed elimination of $T$. dimidiata from the coastal region will require a strong and concerted effort to replicate the results obtained in a few parishes to the entire region. Vector control in other regions also needs to be strengthened, not only in the southern highland valleys, but critically in the Amazon region as well. Control of $R$. ecuadoriensis with insecticide spraying in southern Ecuador has been met with mixed success $[17,34]$, possibly due to a rather intrusive behaviour. Similarly, limited house infestation has been observed in the Amazon region, but several opportunistic sylvatic vector species can invade houses to feed on humans, and will require alternative strategies to be implemented for their control [34, 35]. Combining information from entomological and epidemiological surveillance is also key to better identify risk areas. Finally, achieving sustainability over time and a wide geographic coverage of surveillance and control activities has been a challenge for many national programmes for Chagas disease control throughout Latin America, as it requires a strong political will and commitment [23, 27, 36].

In conclusion, the analysis of national epidemiologic and entomologic surveillance data confirmed the presence of at least three distinct Chagas disease transmission scenarios in Ecuador. Importantly, the Amazon region is emerging as a high priority area, where nearly half of $T$. cruzi infection cases originate. The coastal region and the southern highland valleys remain two of the historically important high-risk area, even though risk seems to have decreased in the later region. Vector control efforts over the past 10 years have been effective in the coastal region, where $T$. dimidiata predominates, but need to be sustained and expanded for the elimination of this vector to be feasible. Also, novel vector control interventions need to be designed to reduce intrusion by several triatomine species present in the Amazon region as well as in southern Ecuador. The successful control of Chagas disease in Ecuador will thus require strong political commitment to sustain current achievements and increase the national coverage of these programmes.

\section{Acknowledgements}

The present work was funded in part by the Proyecto Prometeo of the Secretaria de Educación Superior, Ciencia, Tecnología of Ecuador to ED.

\section{References}

1. Rassi A Jr, Rassi A, Marin-Neto JA. Chagas disease. Lancet 2010: 375: 1388-1402. 
2. WHO. Chagas disease in Latin America: an epidemiological update based on 2010 estimates. Wkly Epidemiol Rec 2015: 90: 33-43.

3. Lee BY, Bacon KM, Bottazzi ME, Hotez PJ. Global economic burden of Chagas disease: a computational simulation model. Lancet Infect Dis 2013: 13: 342-348.

4. Hotez PJ, Bottazzi ME, Franco-Paredes C, Ault SK, Periago MR. The neglected tropical diseases of Latin America and the Caribbean: a review of disease burden and distribution and a roadmap for control and elimination. PLoS Negl Trop Dis 2008: 2: e300.

5. Hotez PJ, Dumonteil E, Woc-Colburn L et al. Chagas disease: "the new HIV/AIDS of the Americas". PLoS Negl Trop Dis 2012: 6: e1498.

6. Aguilar VH, Abad-Franch F, Racines VJ \& Paucar CA (1999) Epidemiology of Chagas disease in Ecuador. A brief review. Mem Inst Oswaldo Cruz 94(Suppl 1), 387-393.

7. Black CL, Ocana-Mayorga S, Riner DK et al. Seroprevalence of Trypanosoma cruzi in rural Ecuador and clustering of seropositivity within households. Am J Trop Med Hyg 2009: 81: 1035-1040.

8. Carrera Vargas C, Orlando Narváez A, Muzzio Aroca J et al. (2015) Seroprevalence of Trypanosoma cruzi infection in school children and in pregnant women from an Amazonian region in Orellana province, Ecuador. Am J Trop Med Hyg 2015: 93: 774-778.

9. Abad-Franch F, Monteiro FA. Biogeography and evolution of Amazonian triatomines (Heteroptera: Reduviidae): implications for Chagas disease surveillance in humid forest ecoregions. Mem Inst Oswaldo Cruz 2007: 102(Suppl 1): 57-70.

10. Abad-Franch F, Paucar A, Carpio C, Cuba CA, Aguilar HM, Miles MA. Biogeography of Triatominae (Hemiptera: Reduviidae) in Ecuador: implications for the design of control strategies. Mem Inst Oswaldo Cruz 2001: 96: 611-620.

11. Bargues MD, Klisiowicz DR, Gonzalez-Candelas F et al. Phylogeography and genetic variations of Triatoma dimidiata, the main Chagas disease vector in Central America, and its position within the genus Triatoma. PLoS Negl Trop Dis 2008: 2: e233.

12. Bargues MD, Marcilla A, Ramsey JM, Dujardin JP, Schofield CJ, Mas-Coma S. Nuclear rDNA-based molecular clock of the evolution of triatominae (Hemiptera: Reduviidae), vectors of Chagas disease. Mem Inst Oswaldo Cruz 2000: 95: 567-573.

13. Monteiro FA, Peretolchina T, Lazoski C et al. Phylogeographic pattern and extensive mitochondrial DNA divergence disclose a species complex within the Chagas disease vector Triatoma dimidiata. PLoS ONE 2013: 8: e70974.

14. Abad-Franch F, Aguilar VH, Paucar CA, Lorosa E, Noireau F. Observations on the domestic ecology of Rhodnius ecuadoriensis (Triatominae). Mem Inst Oswaldo Cruz 2002: 97: 199-202.

15. Abad-Franch F, Noireau F, Paucar A, Aguilar HM, Carpio $\mathrm{C}$, Racines J. The use of live-bait traps for the study of sylvatic Rhodnius populations (Hemiptera: Reduviidae) in palm trees. Trans R Soc Trop Med Hyg 2000: 94: 629-630.
16. Cuba Cuba CA, Vargas F, Roldan J, Ampuero C. Domestic Rhodnius ecuadoriensis (Hemiptera, Reduviidae) infestation in Northern Peru: a comparative trial of detection methods during a six-month follow-up. Rev Inst Med Trop Sao Paulo 2003: 45: 85-90.

17. Grijalva MJ, Palomeque-Rodriguez FS, Costales JA, Davila S, Arcos-Teran L. High household infestation rates by synanthropic vectors of Chagas disease in southern Ecuador. J Med Entomol 2005: 42: 68-74.

18. Grijalva MJ, Suarez-Davalos V, Villacis AG, OcanaMayorga S, Dangles O. Ecological factors related to the widespread distribution of sylvatic Rhodnius ecuadoriensis populations in southern Ecuador. Parasit Vectors 2012: 5: 17.

19. Ministerio de Salud Pública. Acuerdo Ministerial $N^{\circ} 0632$ del 31 de octubre del 2003. Ministerio de Salud Pública: Quito, Ecuador, 2003.

20. Abad-Franch F \& Aguilar HM. Control de la enfermedad de Chagas en el Ecuador, OPS/OMS-Ministerio de Salud Publica del Ecuador, 2003, 70pp.

21. Acquatella H, Catalioti F, Gomez-Mancebo JR, Davalos V, Villalobos L. Long-term control of Chagas disease in Venezuela: effects on serologic findings, electrocardiographic abnormalities, and clinical outcome. Circulation 1987: 76: 556-562.

22. Dias JC, Silveira AC, Schofield CJ. The impact of Chagas disease control in Latin America: a review. Mem Inst Oswaldo Cruz 2002: 97: 603-612.

23. Espinoza N, Borras R, Abad-Franch F. Chagas disease vector control in a hyperendemic setting: the first 11 years of intervention in Cochabamba, Bolivia. PLoS Negl Trop Dis 2014: 8: e2782.

24. Guhl F, Restrepo M, Angulo VM, Antunes CM, CampbellLendrum D, Davies CR. Lessons from a national survey of Chagas disease transmission risk in Colombia. Trends Parasitol 2005: 21: 259-262.

25. Hashimoto K, Alvarez H, Nakagawa J et al. Vector control intervention towards interruption of transmission of Chagas disease by Rhodnius prolixus, main vector in Guatemala. Mem Inst Oswaldo Cruz 2012: 107: 877-887.

26. Hashimoto K, Zuniga C, Nakamura J, Hanada K. Integrating an infectious disease programme into the primary health care service: a retrospective analysis of Chagas disease community-based surveillance in Honduras. BMC Health Serv Res 2015: 15: 116.

27. Segura EL, Cura EN, Estani SA et al. Long-term effects of a nationwide control program on the seropositivity for Trypanosoma cruzi infection in young men from Argentina. Am J Trop Med Hyg 2000: 62: 353-362.

28. Ministerio de Salud Pública. Manual de procedimientos, enfermedades transmitidas por vectores. Dirección Nacional de Vigilancia Epidemiológica, Ministerio de Salud Pública: Quito, Ecuador, 2004.

29. Team QGis. Quantum GIS Geographic Information System, Open Source Geospatial Foundation Project, 2011. (Available from: http://www.qgis.osgeo.org.) [30 Oct 2015] 
L. Quinde-Calderón et al. Chagas disease in Ecuador

30. Guevara A, Moreira J, Criollo $\mathrm{H}$ et al. First description of Trypanosoma cruzi human infection in Esmeraldas province, Ecuador. Parasit Vectors 2014: 7: 358.

31. Grijalva MJ, Escalante L, Paredes RA et al. Seroprevalence and risk factors for Trypanosoma cruzi infection in the Amazon region of Ecuador. Am J Trop Med Hyg 2003: 69: 380-385.

32. Guevara AG, Atherton RD, Wauters MA et al. Seroepidemiological study of chagas disease in the southern Amazon region of Ecuador. Trop Med Health 2013: 41: 21-25.

33. Costales JA, Sanchez-Gomez A, Silva-Aycaguer LC et al. A national survey to determine prevalence of Trypanosoma cruzi infection among pregnant women in Ecuador. Am J Trop Med Hyg 2015: 92: 807-810.

34. Nieto-Sanchez C, Baus EG, Guerrero D \& Grijalva MJ. Positive deviance study to inform a Chagas disease control program in southern Ecuador. Mem Inst Oswaldo Cruz 2015: 110: 299-309.

35. Waleckx E, Gourbière S, Dumonteil E. Intrusive triatomines and the challenge of adapting vector control practices. Mem Inst Oswaldo Cruz 2015: 110: 324-338.

36. Pinto Dias JC. Chagas disease: successes and challenges. Cad Saude Publica 2006: 22: 2020-2021.

Corresponding Author Eric Dumonteil, Laboratorio de Parasitología, Centro de Investigaciones Regionales "Dr. Hideyo Noguchi”, Universidad Autónoma de Yucatán, Ave. Itzaes \#490x59, 97000 Mérida, Yucatan, Mexico. Tel.: +52 9999245910 ; Fax: +52 999923 6120; E-mail: oliver@uady.mx 